\title{
En kvinne med ensidig hodepine
}

\author{
En kvinne hadde kronisk ensidig hodepine som etter flere år endret \\ karakter og gikk over til å bli anfallsvis og mer intens. Etter over 20 år \\ fikk hun riktig diagnose og behandling.
}

Se kommentar side 696 og kunnskapsprøve på www.tidsskriftet.no/quiz

\section{Kai Ivar Müller}

kai.ivar.muller@unn.no

Nevrologisk avdeling

Universitetssykehuset Nord-Norge

9038 Troms $\varnothing$

\section{Svein Ivar Bekkelund}

Nevrologisk avdeling

Universitetssykehuset Nord-Norge

og

Institutt for klinisk medisin

Universitetet i Tromsø

En kvinne i slutten av 50-årene som tidligere hadde vært plaget med kronisk ensidig hodepine i mange år, oppsøkte sin fastlege pga. anfallsvis og intens venstresidig hodepine. Hodepinen var ledsaget av konjunktival injeksjon, tåreflod og nesesekresjon på samme side. Etter å ha konferert med nevrolog ble fastlegens mistanke rettet mot migrene og klasehodepine, men til tross for behandling med sumatriptan nesespray og oksygen, var hodepinen like intens. Etter anbefaling fra nevrolog ble det forsøkt profylaktisk behandling med topiramat uten at pasienten ble bedre. Noen uker etter et mislykket behandlingsforsøk med topiramat ble pasienten på grunn av intraktabel hodepine innlagt i sykehus. Det var da gått to år siden pasienten på grunn av anfallsvis venstresidig hodepine første gang var til konsultasjon hos sin fastlege. I nevrologisk journal beskrives en anfallsvis hodepine lokalisert til venstre orbita og periorbitalt. Anfallene som kom fire til fem ganger per døgn, ble beskrevet som svært intense, og varte 10-20 minutter. Ledsagende symptomer var tåreflod og nesesekret på samme side. Hodepinen forekom aldri på høyre side. Blodtrykk, somatisk og nevrologisk undersøkelse var normale, likeså MR av hjernen.

Det ble startet opp med indometacin $25 \mathrm{mg}$ tre ganger daglig som raskt ga betydelig bedring, og diagnosen passet med kronisk paroksysmal hemikrani. Ved utskrivning var indometacin blitt trappet opp til $50 \mathrm{mg}$ tre ganger daglig. I oppfølgingstiden var hun fortsatt plaget, og fikk regelmessig oksygen og smertestillende behandling på legevakten. Fordi behandling med indometacin ikke ga adekvat smertestillende effekt, ble diagnosen revurdert og klasehodepine igjen foreslått ved konsultasjon hos nevrolog fem måneder etter utskrivningen. Hun gikk deretter til flere oppfølgende konsultasjoner både hos nevrolog og fastlege uten at man kom til mål med behandlingen, inntil det ved kontroll hos nevrolog ett år og fire måneder etter utskrivningen kom frem at hun pga. dyspepsiplager unnlot å ta indometacin regelmessig. Dosen ble økt opptil grensen for utvikling av bivirkninger, og tilpasset ved at halvparten av døgndosen ble administrert som stikkpille om kvelden. Betydningen av å ta medisinen regelmessig ble også presisert overfor pasienten. Selv om hodepinen ikke forsvant helt, avtok hyppigheten av anfallene i tillegg til at smertene var mildere og lettere å leve med (fig 1).

Hos pasienter med kronisk ensidig hodepine som ikke skifter side, bør man i tillegg til klinisk nevrologisk undersøkelse bestille bildediagnostisk utredning av hodet, fortrinnsvis MR-undersøkelse, for å utelukke primære patologiske forhold i hjernen som aneurismer, arteriovenøse malformasjoner og intrakraniale svulster $(1,2)$. Dersom strukturelle hjernesykdommer utelukkes, bør primære former for hodepine overveies. I tabell 1 er det gitt en oversikt over viktige kjennetegn ved noen ensidige primære hodepiner basert på internasjonale klassifikasjonskriterier (2-5). Tabellen viser også dokumentert farmakologisk behandling ved noen viktige ensidige hodepineformer (6-10). Ensidig hodepine er vanlig ved både migrene og klasehodepine, mens tilstedeværelse av kraniale autonome symptomer på samme side er et viktig kjennetegn ved klasehodepine (3).

Pasienten hadde ikke nytte av oksygen som er et godt behandlingsalternativ av hodepineanfall ved klasehodepine (11). Ved manglende respons på medikamentell behandling av primære hodepineformer som migrene og klasehodepine, bør diagnosen revurderes. Varigheten av hodepinen gir viktig diagnostisk informasjon ved anfallsvis hodepine (2-5) (tab 1). I tillegg er det viktig å vurdere pasientens etterlevelse av behandlingen. I dette tilfellet tok det tid før man avdekket at uregelmessig inntak av indometacin pga. bivirkninger var årsaken til manglende behandlingseffekt. En konsekvens av dette var at behandlingen ble foreskrevet på feilaktig grunnlag. Først etter at behandlingen ble individuelt tilpasset med bruk av stikkpille, avtok de gastrointestinale plagene, og hodepineplagene avtok.

En nærmere kartlegging av sykehistorien med pasientsamtaler og gjennomgang av primærlegejournalen i oppfølgingsperioden etter at pasienten var tilfredsstillende behandlet med indometacin, viste at pasienten også tidligere hadde gjennomgått flere mislykkede behandlingsforsøk mot kronisk daglig hodepine ved det samme legekontoret (fig 1). Det er registrert flere konsultasjoner i primærlegejournalen over en 15-årsperiode med beskrivelse av vedvarende venstresidig hodepine ledsaget av muskulære smerter $i$ venstre del av nakken, venstre skulder og overarm (fig 1). Ved en anledning var det under hodepineforverring bemerket tåreflod fra venstre øye. Hodepinen varierte $i$ intensitet, og forverringene kunne vare opptil en måned om gangen i dette tidsrommet. $\mathrm{Pa}$ sienten ble behandlet med reseptfrie smertestillende medisiner lparacetamol og ibuprofen), naproksen og diklofenak, fysikalsk behandling og manuell terapi uten at dette bedret plagene. Aktuelle diagnoser som i denne perioden er anført i primærlegejournalen, er atypisk tensjonshodepine, migrene og nakkesmerter. CT av hjernen og røntgenundersøkelse av nakken var normale.

Etter 15 år med kronisk venstresidig hodepine fikk pasienten forskrevet COX-2-hemmeren rofecoxib av sin fastlege, og ble kvitt hodepinen kort tid etterpå. Da hun slapp opp for medisinen en måned senere, kom hodepinen tilbake. Deretter ble hun behandlet med rofecoxib sammenhengende i 14 måneder. I denne perioden var hun smertefri. Pasienten måtte slutte med rofecoxib da medikamentet ble avregistrert og trukket fra markedet. Etter at hun sluttet med COX2-hemmeren, blusset hodepinen opp i form av kortvarige, intense og ensidige hodepineanfall ledsaget av tåreflod, nesesekresjon og ptose på samme side. Det ble av primærlege på nytt forsøkt fysioterapi, paracetamol 


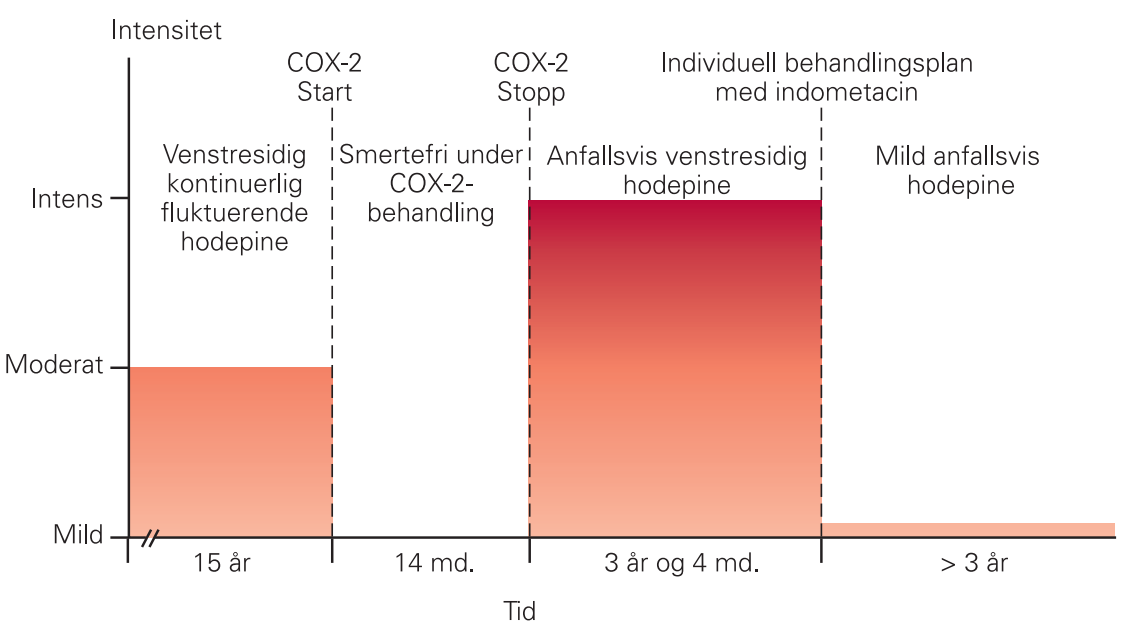

Figur 1 Pasientens hodepine endret karakter og intensitet over tid ptose og andre kraniale autonome symptomer på samme side er vanlig, og forekommer spesielt ved eksaserbasjoner, men kan opptre sjelden eller mangle helt hos noen (5). Ved hemicrania continua, som sannsynligvis er underdiagnostisert, ser man vanligvis full terapeutisk effekt av indometacin i terapeutiske doser (14). Ved kronisk ensidig hodepine og mistanke om hemicrania continua er det viktig å forsøke slik behandling (14). Selv om primærlegen ikke hadde vurdert hemicrania continua som diagnose, mener vi at dette var den sannsynlige årsaken til pasientens tidligere plager, og at indometacin burde ha vært forsøkt. Grunnen til at indometacin ikke ble forsøkt var nok fordi hemicrania continua var lite kjent på det tidspunktet, samtidig som klassifikasjonskriteriene for hodepiner også for første gang ble publisert i denne perioden.

Siden hemicrania continua er ensidig, varierer $\mathrm{i}$ intensitet og kan gi migrenesymptomer som aura, kvalme, lyd- og lysoverfølsomhet, kan den forveksles med migrene (10). Det at hodepinen hos vår pasient aldri har skiftet side, utelukker heller ikke migrene, selv om de fleste opplever at migreneanfall kan skifte side $(3,15)$. Typisk migrene, dvs. ensidig pulserende intens hodepine med varighet mellom fire timer og tre døgn er ikke beskrevet hos denne pasienten (3) (tab 1). Hun har heller ikke hatt andre typiske migrenesymptomer eller merket effekt av migrenemedisin.

\section{Diskusjon}

Den endelige diagnosen passet best med kronisk paroksysmal hemikrani, en primær hodepine som først ble beskrevet av Sjaastad \& Dale i 1974 (16). Anfallene varer vanligvis kortere enn ved klasehodepine, 2-30 minutter, kommer hyppigere og går $\mathrm{i}$ motsetning til klasehodepine som oftest ikke i remisjon. Denne hodepinen, som vanligvis

Tabell 1 Typiske kjennetegn og vanlig farmakologisk behandling ved noen primære hodepineformer som opptrer ensidig (2-10)

\begin{tabular}{|c|c|c|c|c|c|c|}
\hline Type hodepine & Varighet & $\begin{array}{l}\text { Ledsagende } \\
\text { symptomer }\end{array}$ & Intensitet & Lokalisasjon & Akutt behandling & $\begin{array}{l}\text { Forebyggende } \\
\text { behandling }\end{array}$ \\
\hline Migrene & 4 timer -3 dager & $\begin{array}{l}\text { Aura, kvalme, } \\
\text { lys-/lydømfintlig- } \\
\text { het, forverres ved } \\
\text { fysisk aktivitet }\end{array}$ & $\begin{array}{l}\text { Moderat til } \\
\text { sterk }\end{array}$ & $\begin{array}{l}\text { Ensidig - } \\
\text { kan skifte side }\end{array}$ & $\begin{array}{l}\text { Acetylsalisylsyre } \\
\text { Paracetamol } \\
\text { Diklofenak } \\
\text { Ibuprofen } \\
\text { Naproksen } \\
\text { Triptaner }{ }^{2}\end{array}$ & $\begin{array}{l}\text { Propranolol } \\
\text { Metoprolol } \\
\text { Flunarizin } \\
\text { Topiramat } \\
\text { Natrium valproat }\end{array}$ \\
\hline Tensjonshodepine & $\begin{array}{l}\text { Episodisk } 30 \text { min-1 uke } \\
\text { Kronisk } \geq 15 \text { dager per } \\
\text { måned i } 3 \text { måneder }\end{array}$ & - & $\begin{array}{l}\text { Mild til } \\
\text { moderat }\end{array}$ & $\begin{array}{l}\text { Tosidig - } \\
\text { kan være ensidig }\end{array}$ & $\begin{array}{l}\text { Acetylsalisylsyre } \\
\text { Ibuprofen }\end{array}$ & Amitriptylin \\
\hline Klasehodepine & $15-180 \mathrm{~min}$ & $\begin{array}{l}\text { Autonome } \\
\text { symptomer }^{1}\end{array}$ & Sterk & $\begin{array}{l}\text { Ensidig innenfor } \\
\text { samme klase }\end{array}$ & $\begin{array}{l}100 \% \text { oksygen } \\
\text { Sumatriptan } \\
\text { Zolmitriptan }\end{array}$ & $\begin{array}{l}\text { Verapamil } \\
\text { Steroider }\end{array}$ \\
\hline $\begin{array}{l}\text { Kronisk paroksysmal } \\
\text { hemikrani }\end{array}$ & $2-30 \min$ & $\begin{array}{l}\text { Autonome } \\
\text { symptomer }\end{array}$ & Sterk & $\begin{array}{l}\text { Ensidig uten } \\
\text { sideskift }\end{array}$ & - & Indometacin \\
\hline Hemicrania continua & Kronisk & $\begin{array}{l}\text { Autonome } \\
\text { symptomer }\end{array}$ & Variabel & $\begin{array}{l}\text { Ensidig uten } \\
\text { sideskift }\end{array}$ & - & Indometacin \\
\hline
\end{tabular}

1 Tåreflod, konjunktival injeksjon, ptose, miose, øyelokksødem, nesesekresjon, nesetetthet, panne- og ansiktssvette på samme side

${ }^{2}$ Almotriptan, eletriptan, frovatriptan, naratriptan, rizatriptan, sumatriptan og zolmitriptan 
er lokalisert temporalt, orbitalt, og/eller frontalt uten sideskifte, er svært intens, og ledsages vanligvis av kraniale autonome symptomer på samme side $(2,3)$ (tab 1).

Kronisk paroksysmal hemikrani går i likhet med hemicrania continua sjelden i remisjon (10). Det er også sjelden man ser overgang fra hemicrania continua til kronisk paroksysmal hemikrani, slik som i dette tilfellet. Episodisk paroksysmal hemikrani som skiller seg fra den kroniske formen ved at den har remisjonsperioder på minimum en måned, kan gå over til å bli kronisk $(2,3)$. Pasienten ble helt anfallsfri mens hun brukte COX-2-hemmeren rofecoxib mot kronisk ensidig hodepine, men hun fikk anfallsvis ensidig hodepine da hun gikk tom for medisinen. Det er derfor noe usikkert om hodepinen gikk spontant i remisjon, eller om symptomene ble effektivt behandlet med denne medisinen. litteraturen er det beskrevet god effekt av COX-2-hemmeren rofecoxib hos enkeltpasienter med hemicrania continua (10).

I tillegg til hemicrania continua, har indometacin også frapperende effekt ved både episodisk og kronisk paroksysmal hemikrani (2). Hos pasienter med ensidig behandlingstrengende hodepine som ikke er sikker migrene, klasehodepine eller har andre kjente årsaker, bør indometacinresponsive hodepiner som hemicrania continua og paroksysmal hemikrani mistenkes. I slike tilfeller bør man utføre indometacintest $(2,14)$. Man kan for eksempel gi $25 \mathrm{mg}$ tre ganger daglig i tre dager, og ved manglende respons $50 \mathrm{mg}$ tre ganger daglig i ytterligere tre dager (17). Siden enkelte pasienter først responderer på doser høyere enn $150 \mathrm{mg}$, kan det være aktuelt å forsøke høyere dosering, for eksempel $75 \mathrm{mg}$ tre ganger daglig i tre dager (2). Siden indometacin også kan utløse hodepine, er det viktig å vurdere muligheten for falskt negative tester, og pga. muligheten for spontan bedring av hodepiner må man være oppmerksom på falskt positive indometacintester. Ved positiv effekt, bør pasienten bruke lavest mulig effektive dose. Dette kan oppnås ved å redusere døgndosen med $25 \mathrm{mg}$ etter 2-4 ukers symptomfrihet. Siden indometacinresponsive hodepiner sjelden går i remisjon, er det vanskelig å gi klare retningslinjer for behandlingsvarighet, men man kan forsøke seponering etter 2-4 måneders symptomfrihet. Indometacintesten er både enkel og nyttig, og kan godt utføres av primærlege.
For å redusere faren for dyspepsi er det viktig å titrere indometacin til lavest effektive dose, og i tillegg informere pasienten om å ta medisinen til måltider. Hos vår pasient ble de øvre gastrointestinale bivirkningene redusert ved bruk av stikkpille om kvelden. Indometacin stikkpiller bør brukes med forsiktighet ved rektal blødning. Hos pasienter som opplever kraftigere dyspepsiplager, kan administrasjon av medikamenter som beskytter ventrikkelslimhinnen som for eksempel $\mathrm{H}_{2}$-blokkere, protonpumpehemmere eller misoprostol være aktuelt.

Vi hadde sannsynligvis oppnådd bedre etterlevelse dersom pasienten var blitt bedre informert om disse bivirkningene, og samtidig lært opp til å justere dosen etter symptomene. I tillegg til gastrointestinale blødninger ved bruk av indometacin bør man også være oppmerksom på blodtrykk og nyresykdom.

Denne kasuistikken viser ulike diagnostiske problemer ved ensidig hodepine som er nyttig å være oppmerksom på i klinisk praksis. Det er ikke uvanlig at primære hodepiner som migrene, klasehodepine og hemicrania continua blir feildiagnostisert $(15,18$, 19). Konsekvenser av feilaktig diagnose kan være kronifisering av hodepinen og redusert livskvalitet. I tillegg til god kunnskap om hodepine og målrettet og nøyaktig anamnese illustrerer denne historien at god etterlevelse og pasientkommunikasjon er avgjørende for et godt resultat.

Indometacintest er en nyttig undersøkelse for å kunne diagnostisere flere typer hodepiner. Både for denne og mange andre pasienter er indometacin effektiv og nødvendig behandling, og det er svært uheldig for pasientene hvis medikamentet i fremtiden vil være vanskeligere tilgjengelig. Fra februar 2010 har indometacin blitt avregistrert i Norge (20). Medikamentet må derfor per i dag søkes på registreringsfritak.

Pasienten har gitt samtykke til at artikkelen blir publisert.

Oppgitte interessekonflikter: Ingen

\section{Litteratur}

1. Favier I, van Vliet JA, Roon $\mathrm{KI}$ et al. Trigeminal autonomic cephalgias due to structural lesions: a review of 31 cases. Arch Neurol 2007; 64: 25-31.

2. Cittadini E, Matharu MS, Goadsby PJ. Paroxysmal hemicrania: a prospective clinical study of 31 cases. Brain 2008: 131: 1142-55.
3. Headache Classification Subcommittee of the International Headache Society. The International Classification of Headache Disorders, $2^{\text {nd }}$ edn Cephalalgia 2004; 24 (suppl. 1): 1-160.

4. Leone M, D'Amico D. Frediani F et al. Clinical considerations on side-locked unilaterality in long lasting primary headaches. Headache 1993; 33 $381-4$

5. Goadsby PJ, Lipton RB. A review of paroxysmal hemicranias, SUNCT syndrome and other shortlasting headaches with autonomic feature, including new cases. Brain 1997; 120: 193-209.

6. Stovner LJ. Hodepine og ansiktssmerter. I: Vilberg A. Norsk legemiddelhåndbok for helsepersonell 2007. Oslo: Foreningen for utgivelse av Norsk legemiddelhåndbok, 2007: 218-22.

7. Fumal A, Schoenen J. Tension-type headache current research and clinical management. Lancet Neurol 2008: 7: 70-83.

8. Evers S, Afra J, Frese A et al. EFNS guideline on the drug treatment of migraine-revised report of an EFNS task force. Eur J Neurol 2009; 16: 968-81.

9. May A, Leone M, Afra J et al. EFNS guidelines on the drug treatment of cluster headache and other trigeminal autonomic cephalalgias. Eur Neurol 2006; 13: 1066-77.

10. Rossi P. Faroni J, Tassorelli $C$ et al. Diagnostic delay and suboptimal management in a referral population with hemicrania continua. Headache 2009; 49: 227-34

11. Cohen AS, Burns B, Goadsby PJ. High-flow oxygen for cluster headache. JAMA 2009: 302: 2451-7.

12. Natoli J, Manack A, Dean B et al. Global prevalence of chronic migraine: a systematic review. Cephalalgia 2009; e-publisert 10.7.2009.

13. Sjaastad O, Spierings ELH. «Hemicrania continua»: another headache absolutely responsive to indomethacin. Cephalalgia 1984; 4: 65-70.

14. Peres MF, Silberstein SD, Nahmias S et al. Hemicrania continua is not that rare. Neurology 2001; 57: $948-51$

15. Leone M, Cecchini AP, Mea E et al. Epidemiology of fixed unilateral headaches. Cephalalgia 2008; 28 (suppl 1): 8-11.

16. Sjaastad 0, Dale I. Evidence for a new (?), treatable headache entity. Headache 1974: 14: 105-8.

17. Stovner LJ, Somerfelt HK. Hodepine. I: Gjerstad L, Skjeldal $\mathrm{OH}$, Helseth E. Nevrologi og nevrokirurgi. Fra barn til voksen. Høvik: Vett \& Viten, 2007 359-70.

18. Klapper JA, Klapper A, Voss T. The misdiagnosis of cluster headache: a nonclinic, population-based, Internet survey. Headache 2000; 40: 730-5.

19. Lipton RB, Scher Al, Steiner TJ et al. Patterns of health care utilization for migraine in England and in the United States. Neurology 2003; 60: 441-8.

20. Statens legemiddelverk. Legemiddelmangel og avregistreringer. www.legemiddelverket.no/ templates/InterPage 32564.aspx\# Legemiddelmangel_og_avregistreringer (30.8.2010).

Mottatt 20.11. 2009 og godkjent 2.9. 2010.

Medisinsk redaktør Siri Lunde. 